\title{
A Gender Gap Grade Analysis of Hard Sciences Courses in a School of Pharmacy
}

\author{
Erika Hahn ${ }^{1}$, Catherine Santanello ${ }^{2}$, Ron Worthington ${ }^{2}$, McKenzie Ferguson ${ }^{2}$ \\ ${ }^{1}$ Country Mart Pharmacy, Bonne Terre, USA \\ ${ }^{2}$ School of Pharmacy, Southern Illinois University Edwardsville, Edwardsville, USA \\ Email: csantan@siue.edu
}

Received July 23 ${ }^{\text {rd }}$, 2013; revised August 23 $3^{\text {rd }}, 2013$; accepted August 30 $0^{\text {th }}, 2013$

\begin{abstract}
Copyright (C) 2013 Erika Hahn et al. This is an open access article distributed under the Creative Commons Attribution License, which permits unrestricted use, distribution, and reproduction in any medium, provided the original work is properly cited.
\end{abstract}

\begin{abstract}
A student survey was conducted to determine perceptions of such things as differential treatment due to gender, level of preparedness for courses in the hard sciences, and gender performances of students in the sciences. Additionally, students' grades of sixteen courses with a heavy hard science focus were analyzed by taking the percent of a letter grade sorted by male or female to determine if there was a significant gender difference in the final grades. Our objectives were to: 1 ) determine if the underrepresentation of women in some health-related jobs is due to discouragement of females to enter these professions or perceptions of success in hard science courses, 2) examine grades in courses with a strong biology and chemistry focus to see if a significant difference due to gender exists. We concluded that a gender gap in hard sciences grades at the School of Pharmacy did exist but the gap was not large and was not present in all courses. The majority of women were not discouraged to pursue a science based career, but there was a difference in the perceived confidence that many females exhibit in the ability to learn material in the hard science courses and in their preparedness for hard science exams.
\end{abstract}

Keywords: Gender Gap; Hard Sciences; Female Underrepresentation; Pharmacy

\section{Introduction}

Economists use the phrase "gender gap" to refer to differences in the outcomes that women and men achieve in their incomes, types of jobs they choose, and the overall percentage of women and men in the workplace (Goldin, 2004). In accordance with this, there is a gender gap stereotype that females do not perform as well as males in some math and science courses (Schiebinger, 2001). Not only do studies conclude that stereotyping exists, the gender gap has been supported by grade evaluations in certain science, technology, engineering, and mathematics (STEM)-related courses in which males have historically outperformed females with respect to exam scores (Else-Quest, Hyde, \& Linn, 2010). This gender gap was found to exist in the United States as well as other countries, but not necessarily globally (Else-Quest, Hyde, \& Linn, 2010). According to their meta-analysis this gap may be narrowing in some mathematics courses such as algebra. However, there were still significant gaps where males outperformed females in the realm of critical thinking skills, complex problem solving, and in self-confidence. Poor course performance by females could be conceived as confirming a negative gender stereotype (Spencer, Steele, \& Quinn, 1999; Beilock, Rydell, \& McConnell, 2007), possibly causing a female to fear being devalued based on her gender (Steele, Spencer, \& Aronson, 2002) and having an impact on her self-confidence to succeed in the hard sciences.

What are the origins of this type of stereotyping? Discrepancies in grades may be, in part, the result of negative messages from elementary teachers that discourage females from pursuing science activities and developing their abilities in these areas (Mullis \& Jenkins, 1988). Shepardson and Pizzini (1992) suggest that science educators exhibit differential treatment of girls and boys in science classes, either consciously and/or subconsciously, which helps to reinforce this gender gap. Sonnert (2009) examined the influence that fathers may have on their children's perceptions towards the sciences. Fathers are more likely to use scientific terms and take advantage of learning opportunities that are related to science and physics in the household environment. Although it wasn't found to make a significant difference between sons and daughters, there still may be an impact of how a father talks to his children and on a child's future views on science and mathematics. In addition to parental influences, factors like the presence or lack of role models and the level of parental education were also seen as influencing one's views of the hard sciences and future occupational choices.

Practice of these stereotypes could cause women to be discouraged from pursuing careers in scientific research or academic positions in pharmacy, engineering, physics, etc., ceding those jobs to men due to their own deflated confidence in these science-related fields. Guelich et al. (2002) reported that women attending medical school were less likely to pursue a career in medical research than men, giving competing family obligations and a lack of confidence in this area as chief reasons. Underrepresentation of women in (STEM)-related jobs is evident in the US as well as other parts of the world (Anita Borg Institute for Women and Technology, 2012). As reported 
by the US Bureau of Labor Statistics in 2010, the percentage of women in science positions still lags behind males in many fields: engineers (12.9\%), dentists (25.3\%), architects (25.8\%), and physicians (32.3\%). These statistics reveal that men continue to dominate the workforce in math/science fields holding greater than $50 \%$ of these careers. The field of Pharmacy differs in that $53 \%$ of those employed in the field of Pharmacy are female. (U.S. Dept. of Labor, 2011) Yet given the flexibility in work scheduling and the high income that many pharmacist positions offer, female presence could be even higher if the various behaviors that discourage women during science studies were absent.

Even though there are numerous studies showing statistical evidence that gender gaps exist, a study conducted by Ferrinman, Lubinski, \& Benbow (2009) suggests it may be due to preference. They found that there was a difference in what men and women desired in order to balance work and family. The groups of men and women studied were top performers in college. As the groups became older adults they found that men put higher priority on work-related needs such as a higher salary, prestige of the organization they work for, and taking risks. Women, on the other hand, want to be satisfied in the workplace, work in a clean environment and obtain respectful relationships with colleagues. As women started having children, their preference shifted to wanting better working hours. Since STEM careers often involve long hours and a competitive environment, women may face greater difficulty in balancing parenting and professional roles than men.

The gender gap between men and women is a multi-faceted issue. As mentioned, it may be due to gender roles and the atmosphere that children grow up in or it may be a matter of choice. In order to further address this issue, additional research needs to be conducted to see if specific groups of students suffer from similar disparities that often exist in the workplace. Following the publication of Miyake et al. (2010) on values affirmation among college science studies, we asked whether students in our doctor of pharmacy program partition in a similar manner by gender. The following study probed whether a perceived gender gap occurs at the Southern Illinois University Edwardsville School of Pharmacy (SIUE SoP) in the hard sciences courses and if the grades earned in the hard sciences courses corresponded to these perceptions.

\section{Methods}

Sixteen courses were selected from fall of 2005 to fall of 2010 for analysis based on the current curriculum during the time of the study. Courses were selected from the first three years of didactic courses of the four year program. Of these sixteen courses, four were considered courses with a heavy math emphasis whereas the remaining courses had a strong science and chemistry focus. The specific course grades were requested from the Registrar's Office for the SIUE SoP and the identities of the students were withheld from the researchers. The research was approved by the Southern Illinois University Edwardsville Institutional Review Board. Required courses were selected by determining if the courses were taught by instructors listed in the Pharmaceutical Science Department. Some courses at the SIUE SoP are mixed Pharmaceutical Science and Pharmacy Practice. Therefore, content to be included in this study was determined by hours taught by a Pharmaceutical Science instructor during the course. The description of high and low science content was also determined by the hours of instruction by a Pharmaceutical Science instructor whereas greater than approximately $50 \%$ of the course hours were considered high science/math content. It was requested that the data include gender and course call number. Students were selected on the basis of attending the School of Pharmacy from its inception date until the present date of the survey (See demographic information, Table 1 and Figure 1). Student grades were sequestered from fall of 2005 to fall of 2010 with a total of six graduating and current classes. The students' grades were analyzed by taking the percent of a letter grade sorted by male or female. For example, if there were one hundred male students, then the number of A grades for the male students would be divided by the total number of male students. This was completed for all courses. Also, courses that were similar in content were combined. For example, Principles of Drug Action is a two semester course with a similar level of scientific rigor therefore combined into one analysis.

In order to analyze the data consistently, data were reviewed according to performance during the respective year in pharmacy school (P1 year, P2 year, P3 year). Due to course changes and inconsistencies for the initial class that entered SIUE School of Pharmacy, the data for year 2005 were removed as well as some of the data from 2006 and 2007.

In addition to determining student grades, a voluntary perception survey was conducted via Survey Monkey and delivered to students via email. The survey questions are presented in Table 2. The questions were not pretested. All current students were asked to participate ( $\mathrm{N}=\sim 320$ students) and were informed that their participation would be anonymous and confidential. Data analysis primarily involved descriptive statistics.

\section{Results}

The survey request was sent to all current SIUE SOP students via e-mail request totaling approximately 320 students.

Table 1.

Admission class demographics.

\begin{tabular}{cccc}
\hline Admission Year & Cumulative GPA & PCAT average & F/M Ratio \\
\hline 2005 & 3.58 & 68 & 1.1 \\
2006 & 3.61 & 73 & 1.5 \\
2007 & 3.61 & 75 & 1.3 \\
2008 & 3.63 & 75 & 1.4 \\
2009 & 3.65 & 68 & 1.2 \\
2010 & 3.54 & 64 & 1.8 \\
\hline
\end{tabular}

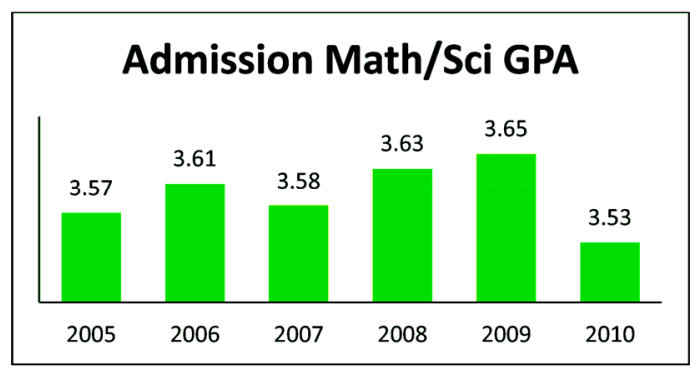

Figure 1.

Admission math/science GPA. 
Table 2.

Perception survey results.

\begin{tabular}{|c|c|c|c|c|c|c|c|c|c|c|}
\hline & \multicolumn{5}{|c|}{ Female \% $(n=65)$} & \multicolumn{5}{|c|}{ Male \% $(n=33)$} \\
\hline & SA & A & $\mathrm{N}$ & DA & SDA & SA & A & $\mathrm{N}$ & DA & SDA \\
\hline I feel WOMEN perform better in hard sciences courses compared to men. & 1.5 & 7.7 & 56.9 & 27.7 & 6.2 & 0.0 & 0 & 57.3 & 33.3 & 9.1 \\
\hline I feel MEN perform better in hard sciences courses compared to women. & 0.0 & 13.8 & 55.4 & 24.6 & 6.2 & 9.1 & 15.2 & 51.5 & 18.6 & 6.1 \\
\hline $\begin{array}{l}\text { My hard sciences grades reflected my actual understanding } \\
\text { of the material in high school. }\end{array}$ & 26.2 & 47.7 & 4.6 & 18.5 & 3.1 & 30.3 & 51.5 & 6.1 & 12.1 & 0 \\
\hline $\begin{array}{l}\text { My hard sciences grades reflected my actual understanding } \\
\text { of the material in pre-pharmacy school. }\end{array}$ & 20.0 & 55.4 & 9.2 & 13.8 & 1.5 & 27.3 & 57.6 & 0 & 15.2 & 0 \\
\hline $\begin{array}{l}\text { My hard sciences grades reflected my actual understanding } \\
\text { of the material in pharmacy school. }\end{array}$ & 12.3 & 55.4 & 15.4 & 16.9 & 0 & 21.2 & 48.5 & 12.1 & 18.2 & 0 \\
\hline I am very confident in learning material in hard science courses. & 12.3 & 46.2 & 18.5 & 23.1 & 0 & 15.2 & 75.8 & 9.1 & 0 & 0 \\
\hline I am usually well prepared for hard sciences exams. & 9.2 & 49.2 & 20.0 & 20.0 & 1.5 & 9.1 & 72.7 & 12.1 & 6.1 & 0 \\
\hline I can learn from any instructor on any subject. & 4.6 & 16.9 & 9.2 & 41.5 & 27.7 & 9.1 & 12.1 & 24.2 & 39.4 & 15.2 \\
\hline I need/want a connection with the instructor to perform well in any course. & 10.8 & 46.2 & 21.5 & 18.5 & 3.1 & 6.1 & 39.4 & 24.2 & 27.3 & 3.0 \\
\hline $\begin{array}{l}\text { I feel that I have been discouraged to pursue a science related } \\
\text { degree based on my gender (any time during my education). }\end{array}$ & 4.6 & 12.3 & 3.1 & 41.5 & 38.5 & 0 & 0 & 6.1 & 33.3 & 60.6 \\
\hline $\begin{array}{l}\text { I feel that I have been encouraged to pursue a science degree } \\
\text { based on my gender. }\end{array}$ & 12.3 & 18.5 & 12.3 & 35.4 & 21.5 & 6.1 & 12.1 & 30.3 & 21.2 & 30.3 \\
\hline
\end{tabular}

Note: SA: Strongly Agree; A: Agree; N: Neutral; DA: Disagree; SDA: Strongly Disagree.

Of these students, 98 responded with 65 female responses and 33 male. A total of 98 students (30\%) completed the survey with the majority being female $(n=65)$.

A total of 6573 grades were reviewed over the 5-year period. A total of 731 grades were removed from analysis due to course changes and variability. Of the remaining 5842 grades evaluated, females accounted for 3355 of the total grades and males accounted for 2487. Figure 1 and Table 2 represent the incoming math/science grade point average (GPA) and the female/male distribution by the admission year into the School of Pharmacy. This data shows that the female:male ratio has steadily increased over the past 5 years indicating that more females are entering the profession of pharmacy. Additionally, though the math/science GPA upon admission decreased in 2010, it has remained fairly consistent.

The data for the 5842 grades evaluated in the P1, P2, and P3 year were presented in Figures 2-4. This data shows that within each year in the pharmacy curriculum, females and males are performing similarly in math/science courses. However, in the P1 year, males exceed females in the number of A grades and females exceed males in the number of $F$ grades (14 females, 2 males). The grades are more evenly distributed among females and males $\mathrm{P} 2$ and $\mathrm{P} 3$ year.

\section{Discussion}

Based on our study results, men outperformed women in five of the seven sample groups (Figures 2-5 and Table 3) and men outperformed women in the overall course grades as well. SIUE School of Pharmacy's therapeutics courses are integrated with pharmacotherapy, clinical therapy and medicinal chemistry. In integrated therapeutics courses with a high content of medicinal chemistry, women scored slightly higher than men with a grade of A and men outperformed women in the B range. Overall, there was a difference in men and women's performance; however these differences were not large.

In the perceptions survey results (Table 2):

- A little over half of both women and men were neutral about their perceptions of which gender performs better in the sciences.

- Men (69.7\% - 81.8\%) and women (67.7\% - 75.4\%) agreed or strongly agreed that their grades reflected what they understood in their coursework prior to pharmacy school or during their pharmacy graduate work. This correlates with Martens et al. (2006) who found that females reported selfsatisfaction with grades and performance when self-affirmation was stronger than existing stereotype threats due to gender,

- In the category of being very confident in learning material in hard science courses, $58.5 \%$ of the women agreed or strongly agreed whereas $91 \%$ of men agreed or strongly agreed. Concurrently, $58.4 \%$ of women and $81.8 \%$ of men agreed or strongly agreed that they felt well prepared for

\section{P1 Math/Science Grade Distribution}

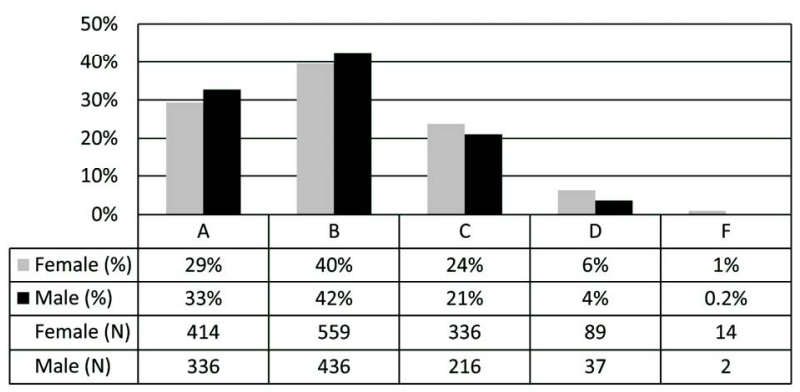

Figure 2.

P1 (first year class) grade distribution 2005 to 2010. 
P2 Math/Science Grade Distribution

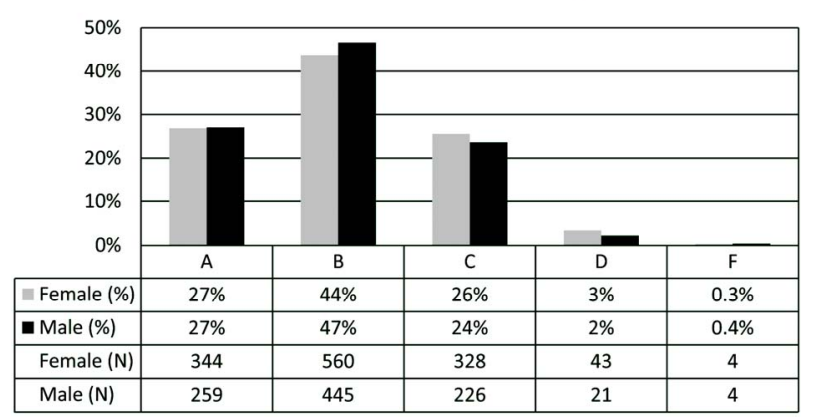

Figure 3.

P2 (second year class) grade distribution 2005 to 2010.

\section{P3 Math/Science Grade Distribution}

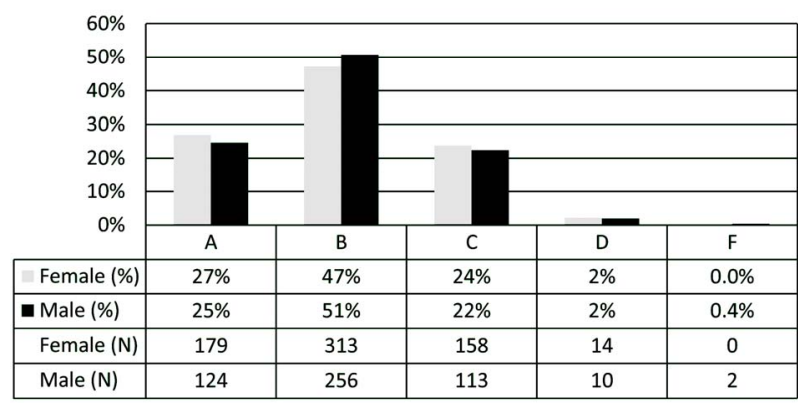

Figure 4.

P3 (third year class) grade distribution 2005 to 2010.

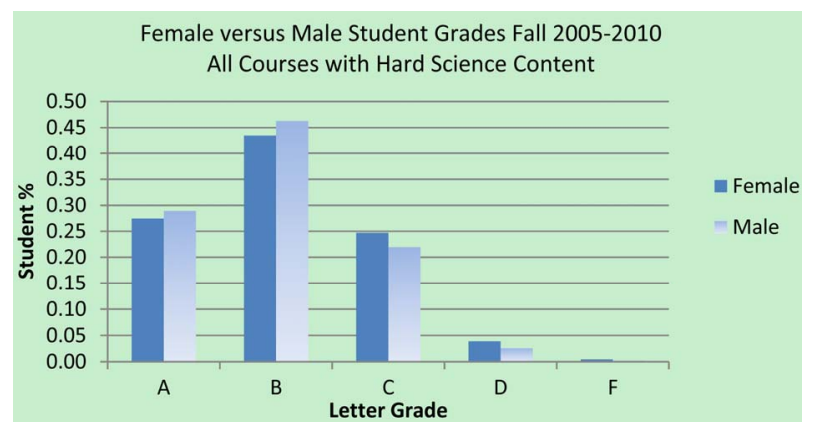

Figure 5.

Grades according to gender.

hard science exams. This conclusion offers support to the theory that men show greater confidence than women in this respect. As previously mentioned, boys may develop greater confidence in STEM because they are more likely to have opportunities to develop these relevant skills (Pajares, 2005) and they may have had greater role models in the sciences at some point in their lives (Sonnert, 2009).

- Overall, neither gender felt that they can learn from all instructors and the majority of women (57\%) and nearly half of the men $(45.5 \%)$ reported needing a connection with the instructor to perform well. This is in concordance with Shea et al. (2003), who found that student-faculty interaction is one of the strongest predictors of perceived learning of the course material and course satisfaction. Some students may relate to certain professors more than others due to things such as gender biases, instructional styles, or personality
Table 3.

Student performance percent by course.

\begin{tabular}{|c|c|c|c|c|}
\hline \multicolumn{5}{|c|}{ Female versus Male Student Grades by Course 2005-2010 } \\
\hline & \multicolumn{2}{|c|}{ \% A Grades } & \multicolumn{2}{|c|}{ \% B Grades } \\
\hline & Female & Male & Female & Male \\
\hline All Courses & 27 & 29 & 43 & 46 \\
\hline Clinical Pharmacokinetics & 63 & 68 & 34 & 29 \\
\hline $\begin{array}{l}\text { Principles of Drug Action- } \\
\text { Medicinal Chemistry }\end{array}$ & 16 & 17 & 40 & 46 \\
\hline $\begin{array}{c}\text { Pharmaceutics \& Pharmacokinetics } \\
\text { I, II, III }\end{array}$ & 17 & 21 & 46 & 51 \\
\hline Biochemical/Biochemistry Principles & 33 & 45 & 47 & 40 \\
\hline Microbiology \& Immunology & 57 & 50 & 36 & 39 \\
\hline $\begin{array}{l}\text { Integrated Therapeutics with High } \\
\text { Medicinal Chemistry Content } \\
\text { Infectious Disease and Oncology }\end{array}$ & 17 & 16 & 44 & 47 \\
\hline Biotechnology & 51 & 55 & 48 & 40 \\
\hline
\end{tabular}

differences and this relationship may enhance their connectedness to the material. There is also evidence that students shift perceptions during graduate school to learning the material rather than focusing on a final grade and the instructional design (Ames \& Archer, 1988).

- None of the men agreed or strongly agreed that they were discouraged to pursue a science career whereas roughly $17 \%$ of women felt that they had been discouraged. Similar research by Spencer, Steele \& Quinn (1999), Beilock, Rydell \& McConnell (2007) and Steele, Spencer \& Aronson (2002) supports the premise that females are sometimes subject to this type of discouragement based on their gender.

Limitations to this study included the lack of evaluation of other factors that could potentially impact grades and survey perceptions, such as the age of students, previous degrees held, and other related demographic data. Also, some students may perform poorly in courses where they do not see real-life applications and aren't intrinsically or extrinsically motivated, resulting in lower grades. Their final grades may not correlate with preparedness or potential to have earned a higher grade. Another limitation is that integrated courses include a combination of both math/science and pharmacy practice-related content, making it difficult to draw conclusions relating to performance without seeing the breakdown of performance in each area. These team-taught courses can also make it hard to determine if specific instructors are hindering or enhancing learning in these courses and makes it difficult to determine if there is a connectedness with an individual instructor resulting in enhanced student performance. Additionally, only a small proportion of the students (30\%) responded to the survey which could render some reporting bias in the collected data.

\section{Conclusion}

After final evaluation, there does appear to be a gender gap in hard sciences grades at the School of Pharmacy. However, this gap is not large and is not present in all classes. Furthermore, there are some courses in which women outperform the men. It also appears that while the majority of women were not 
discouraged to pursue a science based career, there does appear to be a difference in the perceived confidence that many females exhibit in the ability to learn material in the hard science courses and in their preparedness for hard science exams. Despite these perceptions, one could conclude that they pursued and achieved admission to pharmacy school due to their own interest in the health sciences. Additionally, women may have chosen the field of pharmacy due to the fact that there is more potential for earning higher wages with better hours compared to other similar health-related careers.

\section{REFERENCES}

Ames, C., \& Archer, J. (1988). Achievement goals in the classroom: Student's learning strategies and motivation processes. Journal of Educational Psychology, 80, 260-267.

http://dx.doi.org/10.1037/0022-0663.80.3.260

Anita Borg Institute for Women and Technology (2012). Solutions to recruit technical women.

http://anitaborg.org/files/Anita-Borg-Inst-Solutions-To-Recruit-Tech nical-Women1.pdf

Beilock, S. L., Rydell, R. J., \& McConnell, A. R. (2007). Stereotype threat and working memory: Mechanisms, alleviation, and spillover. Journal of Experimental Psychology General, 136, 256-276. http://dx.doi.org/10.1037/0096-3445.136.2.256

Else-Quest, N. M., Hyde, J. S., \& Linn, M. C. (2010). Cross-national patterns of gender difference in mathematics: A meta-analysis. American Psychological Association, 136, 103-127.

Ferrinman, K., Lubinski, D., \& Benbow, C. (2009). Work preferences, life values, and personal views of top math/science graduate students and the profoundly gifted: Developmental changes and gender differences during emerging adulthood and parenthood. Journal of Personality and Social Psychology, 97, 517-532. http://dx.doi.org/10.1037/a0016030

Goldin, C. (2004). Gender gap: The concise encyclopedia of economics. http://www.econlib.org/library/Enc1/GenderGap.html
Guelich, J. M., Singer, B. H., Castro, M. C., \& Rosenberg, L. E. (2002). A gender gap in the next generation of physician-scientists: Medical student interest and participation in research. Journal of Investigative Medicine, 50, 412-418. http://dx.doi.org/10.2310/6650.2002.32475

Martens, A., Johns, M., Greenberg, J., \& Schimel, J. (2006). Combating stereotype threat: The effect of self-affirmation on women's intellectual performance. Journal of Experimental Social Psychology, 46, 236-243. http://dx.doi.org/10.1016/j.jesp.2005.04.010

Miyake, A., Kost-Smith, L. E., Finkelstein, N. D., Pollock, S. J., Cohen, G. L., \& Ito, T. A. (2010). Reducing the gender achievement gap in college science: A classroom study of values affirmation. Science, 2330, 1234-1237. http://dx.doi.org/10.1126/science.1195996

Mullis, I., \& Jenkins, L. (1988). The science report card (Report No. 17-S-01). Princeton, NJ: Educational Testing Service.

Pajares, F. (2005). Gender differences in mathematics self-efficacy beliefs. In A. M. Gallagher, \& J. C. Kaufman (eds.), Gender differences in mathematics: An integrative psychological approach. Boston, MA: Cambridge University Press.

Schiebinger, L. L. (2001). Has feminism changed science? Cambridge, MA: Harvard University Press.

Shea, P., Pickett, A., \& Pelz, W. (2003). A follow-up investigation of "teaching presence" in the SUNY Learning Network. Journal of Asynchronous Learning Networks, 7, 61-80.

Shepardson, D. P., \& Pizzini, E. L. (1992). Gender bias in female elementary teachers' perceptions of the scientific ability of students. Science Education, 76, 147-153. http://dx.doi.org/10.1002/sce.3730760204

Sonnert, G. (2009). Parents who influence their children to become scientists: Effects of gender and parental education. Social Studies of Science, 39, 927-941. http://dx.doi.org/10.1177/0306312709335843

Spencer, S. J, Steele, C. M., \& Quinn, J. (1999).Stereotype threat and women's math performance. Journal of Experimental and Social Psychology, 35, 4-28. http://dx.doi.org/10.1006/jesp.1998.1373

US Bureau of Labor Statistics (2010). BLS information. http://www.bls.gov/bls/blswage.htm

US Department of Labor (2011). Women in the labor force: A databook. http://www.bls.gov/cps/wlf-databook2010.htm 